\title{
Assessment of attitude towards innovative approaches related to nursing care in intensive care units among staff nurses of P.B.M. Hospital, Bikaner
}

\author{
Jangir $\mathbf{G}^{1}$, Yadav $\mathbf{A}^{2}$ \\ ${ }^{1}$ Ghanshyam Jangir, Lecturer at Govt. College of Nursing, S.P. Medical College, Bikaner, ${ }^{2}$ Dr. Ashok Yadav, Lecturer at \\ Govt. College of Nursing, S.M.S. Hospital, Jaipur, Rajasthan, India.
}

Corresponding Author: Ghanshyam Jangir, Lecturer, Govt. College of Nursing, S.P.M.C., Bikaner, Rajasthan, E-mail: ghanshyamjangir901@gmail.com

\begin{abstract}
Back ground: Innovation is process of developing new approaches, technologies and ways of working. It can apply to tools and technologies and processes, or the way anorganization or an individual behaves works or acts. Nursing care is changing in the face of technology, and innovation is the most important tool for improving the quality of care of community. Creativity and innovation are needed to continue the expression of genuine care and concern, not only through human contact, but also through the use of technology.Technology and its increased use in the healthcare field is constantly evolving and changing. The attitudes of the staff nurses can impact the successful use of that technology and thereby improve not only competency, but also job satisfaction, quality of nursing care. Objectives: 1 . To assess the attitude towards innovative approaches related to nursing care in Intensive Care Unit (ICUs) among the staff nurses working in PBM hospital. 2. To associate the attitude towards innovative approaches among staff nurseswith selected background variable.3. To conduct the seminar on innovative approaches related to nursing care inICUs. Materials and Methods: Using non experimental study with descriptive design data were collected from 100 staff nurses working in ICUs. Likert type scale was used to collect data on attitude and structured questionnaire for back ground variable. Analysis of data was done using descriptive and inferential statistics. Results: Analysis of data showed statistically significant association between attitude towards innovative approaches and professional education and participation in continuing education among nurses. Study findings depicts positive attitude of nurses towards innovation in nursing care, whereas nurses working in ICUs have limited access to innovative and evidence based information. Conclusion: The study concluded that the attitude of staff nurses towards innovation in nursing care need to be enhanced by conducting educational training program and seminar on innovation in nursing care. There must be adequate access to information on innovative and evidenced based practice in nursing care.
\end{abstract}

Keywords: Attitude, Innovative approaches, Evidenced based practice, Staff nurses, Nursing care, ICUs.

\section{Introduction}

Today the importance of scientific knowledge has been increasing and health care applications are changing rapidly. International Council of Nurses defines innovation as new approaches, technologies and ways of working development process. Innovation is vital in terms of improving the quality of nursing care. Nurses worldwide are engaged in innovative activities on a daily basis; activities motivated by the desire to improve the patient care outcomes and the need to reduce costs to health system. Many of these initiatives have resulted

Manuscript received: $10^{\text {th }}$ November 2018

Reviewed: $20^{\text {th }}$ November 2018

Author Corrected: $29^{\text {th }}$ November 2018

Accepted for Publication: $5^{\text {th }}$ December 2018 in significant improvements in the health of patients, population and health systems. Nurses live ina world that is constantly changing to make a significant difference to the world's people. Within today's context of scare resources, continuous change and expanding knowledge, innovation is truly expectation.

Nursing innovation is a fundamental source of progress for healthcare systems around the world. Nurses work in all settings with all types of patients, families, communities, healthcare personnel and personnel in other sectors. As such, nurses are critically positioned to provide creative and innovative solutions that make a 


\section{Original Research Article}

real difference to the day to day lives of the patients, organizations, community and profession. The increasingly aging population, chronic treatment of acute illness depending on which treatment applications have changed the perspective on the quality of the patient's care and maintenance.

Innovation is the most important tool for improving the community's quality of life. It is therefore felt need to conduct the studies among staff nurses to assess the attitude towards innovative approaches in nursing care [1].

In clinical practice, technology has posed some barriers to frontline nurses in adopting telehealth, as seen in the slow implementation of telehealth in the United Kingdom. Telehealth has been defined as the remote exchange of data and information between patients and healthcare professionals to assist in diagnosis and management of health conditions [2].

Taylor and colleagues (2015) conducted a thematic analysis of qualitative interviews to identify barriers to the successful adoption of telehealth. Semi-structured interviews were conducted with 105 registered nurses located in four community clinics in the United Kingdom. Results of the study indicated that frontline staff acceptance of telehealth was fragile, uncertain, and was hindered by organizational, professional and technological barriers [3]. In this study, we aim to determine the attitude of staff nurses towards different aspects of innovation in practice of nursing care in ICUs.

\section{Materials and Methods}

This descriptive study carried out in selected ICUs of P.B.M. Hospital Bikaner with aim to assess the attitude of staff nurses towards innovative approaches and EBP in nursing care.

Sample: samples selected in study were 100 male and female staff nurses those working in ICUs of hospital. Selection of samples was done by simple random sampling those fulfills inclusion and exclusion criteria.

Inclusion criteria: Staff nurses those working ICUs and willing to participate in study.
Data collection: Background data were collected from samples by structured questionnaire to collect information on age, sex, professional education, participation in continuing education, working hours per week, area of service and patient care age group.

Attitude towards innovation was assessed by 5 points likert type scale which consists of six component of attitude towards innovation ie.

Personal belief and Knowledge about Innovation and Evidenced based practice, Self efficacy in use of innovative approaches, Barriers to adopting innovation in practice, Personal use and understanding of clinical practice guidelines, Availability to access innovative and evidence based practice information, and attitude towards new practices. Total maximum score on tool was 225 with minimum 45 .

A score of 45 shows strong negative attitude, 45 to 90 negative attitude, 90-135 neutral attitude, 135 to 180 positive attitude and score of 180 to 225 shows strong positive attitude towards innovation in nursing care.

Questionnaire was designed after review of the literature on attitude towards innovative approaches. Content validity of tool was obtained by experts in subjects and reliability of tool was satisfied by cronbach's alpha.

A pilot study was conducted on a group of $10 \%$ sample to test its clarity and feasibility. Difficult non relevant statement were then modified and replaced. Ethical considerations were followed throughout the study steps.

Statistical Analysis- The data was recorded into an Excel spread sheet after collection and was then analyzed using statistical software SPSS.

Descriptive statistics like frequency and percentage while continuous variable were reported using mean and standard deviation.

Association between the variable were reported using chi square test for categories variable and pared t test for continuous variable.

Distribution of staff nurses in relation to their age group reveals that $16 \%$ nurses are in age group 20-29 years, $64 \%$ nurses in $40-49$ years, and $1 \%$ staff nurses in above 50 year age group, $50 \%$ are male and $50 \%$ are female, in relation to their professional education describes that $61 \%$ staff nurses diploma level, $27 \%$ are Baccalaureate, $12 \%$ are P.B.B. Sc, participation in continuing education $31 \%$ staff nurses participates regularly in continuing education programme and 69 $\%$ staff nurses does not. Distribution of staff nurses in relation to working hoursper week shows that $4 \%$ nurses works $<20 \mathrm{hrs}, 29 \%$ nurses works $20-30 \mathrm{hrs}, 63 \%$ nurses works $30-40 \mathrm{hrs}$ and $4 \%$ nurses works $>40 \mathrm{hrs}$ per week, in relation to 


\section{Results}

Table-1: Distribution of samples according to their background variables $(\mathrm{N}=100)$.

\begin{tabular}{|c|c|c|c|}
\hline & & $\mathbf{N}$ & $\%$ \\
\hline \multirow[t]{4}{*}{ Age } & $20-29$ yrs & 16 & 16 \\
\hline & $30-39$ yrs & 64 & 64 \\
\hline & $40-49$ yrs & 19 & 19 \\
\hline & Above 50 yrs & 1 & 1 \\
\hline \multirow[t]{2}{*}{ Sex } & Male & 50 & 50 \\
\hline & Female & 50 & 50 \\
\hline \multirow[t]{4}{*}{ Education } & Diploma & 61 & 61 \\
\hline & Baccalaureate & 27 & 27 \\
\hline & P.B.B.Sc. N & 12 & 12 \\
\hline & Master degree & 0 & 0 \\
\hline \multirow[t]{2}{*}{ Participation in C.E. } & Yes & 31 & 31 \\
\hline & No & 69 & 69 \\
\hline \multirow[t]{4}{*}{ Work hours per week } & $<20$ & 4 & 4 \\
\hline & $20-30$ & 29 & 29 \\
\hline & $30-40$ & 63 & 63 \\
\hline & $>40$ & 4 & 4 \\
\hline \multirow[t]{4}{*}{ Area of service } & Orthopedic & 19 & 19 \\
\hline & Neurological & 27 & 27 \\
\hline & Cardiovascular & 29 & 29 \\
\hline & Others & 25 & 25 \\
\hline \multirow[t]{4}{*}{ Patient care age group } & Pediatric & 24 & 24 \\
\hline & Adult & 50 & 50 \\
\hline & Geriatric & 25 & 25 \\
\hline & Others & 1 & 1 \\
\hline
\end{tabular}

area of service reveals that $19 \%$ nurses works in orthopedic, $27 \%$ nurses works in neurological, $29 \%$ nurses works in cardiovascular and 25\% staff nurses works in other areas andin considering care of patient in different age group indicates that $24 \%$ nurses care to pediatric group, $50 \%$ nurses cares to adult group, $25 \%$ nurses cares to geriatric group and $1 \%$ nurses care to others.

Table-2: Over all Attitude score towards innovative approaches.

\begin{tabular}{|c|l|c|c|c|}
\hline No & Attitude & Mean & Mean \% & SD \\
\hline 1 & $\begin{array}{l}\text { Personal belief and Knowledge about Innovation and Evidenced based } \\
\text { practice. }\end{array}$ & 3.58 & 71.5 & 1.02 \\
\hline 2 & Self efficacy in use of innovative approaches & 3.40 & 68 & 0.93 \\
\hline 3 & Barriers to adopting innovation in practice & 3.03 & 60.6 & 0.76 \\
\hline 4 & Personal use and understanding of clinical practice guidelines. & 3.26 & 65.3 & 0.91 \\
\hline 5 & $\begin{array}{l}\text { Availability to access innovative and evidence based practice } \\
\text { information }\end{array}$ & 2.8 & 56 & 0.9 \\
\hline 6 & belief in new practices & 3.83 & 76.6 & .86 \\
\hline
\end{tabular}


Original Research Article

Table-3: Category of Attitude of staff nurses towards innovative approaches.

\begin{tabular}{|l|c|c|}
\hline & Frequency & Percent \\
\hline Neutral & 31 & 31.0 \\
\hline Positive & 58 & 58.0 \\
\hline Strong Positive & 11 & 11.0 \\
\hline Total & $\mathbf{1 0 0}$ & $\mathbf{1 0 0}$ \\
\hline
\end{tabular}

The above table assesses the category wise attitude of nurses towards innovative approaches. 31 staff nurses have neutral attitude, 58 staff nurses have positive attitude and 11 staff nurses have strong positive attitude.

Table-4: Association of attitude towards innovative approaches among staff nurses with back ground variable.

\begin{tabular}{|c|c|c|c|c|c|c|c|c|}
\hline \multirow[t]{2}{*}{ S.N. } & \multicolumn{2}{|c|}{ Back ground variable } & \multicolumn{3}{|c|}{ Attitude } & \multirow[t]{2}{*}{ Value } & \multirow[t]{2}{*}{ Df. } & \\
\hline & & & Neutral & Positive & $\begin{array}{l}\text { Strong } \\
\text { Positive }\end{array}$ & & & \\
\hline \multirow[t]{4}{*}{1} & \multirow[t]{4}{*}{ Age } & $20-29$ yrs & 2 & 10 & 4 & \multirow[t]{4}{*}{8.140} & \multirow[t]{4}{*}{6} & \multirow{4}{*}{$\begin{array}{l}12.6 \\
\text { NS }\end{array}$} \\
\hline & & $30-39$ yrs & 22 & 35 & 7 & & & \\
\hline & & $40-49$ yrs & 7 & 12 & 0 & & & \\
\hline & & Above 50 yrs & 0 & 1 & 0 & & & \\
\hline \multirow[t]{2}{*}{2} & \multirow[t]{2}{*}{ Sex } & Male & 13 & 32 & 5 & \multirow[t]{2}{*}{1.518} & \multirow[t]{2}{*}{2} & 5.99 \\
\hline & & Female & 18 & 26 & 6 & & & NS \\
\hline \multirow[t]{4}{*}{3} & \multirow{4}{*}{$\begin{array}{l}\text { Professional } \\
\text { Education }\end{array}$} & Diploma & 29 & 32 & 0 & \multirow[t]{4}{*}{40.075} & \multirow[t]{4}{*}{4} & \multirow{4}{*}{$\begin{array}{c}9.49 \\
S^{*}\end{array}$} \\
\hline & & Baccalaureate & 2 & 15 & 10 & & & \\
\hline & & P.B.B.Sc. N & 0 & 11 & 1 & & & \\
\hline & & Master degree & 0 & 0 & 0 & & & \\
\hline \multirow[t]{2}{*}{4} & \multirow{2}{*}{$\begin{array}{l}\text { Participation in } \\
\text { Cont. Edu. }\end{array}$} & Yes & 1 & 20 & 10 & \multirow[t]{2}{*}{29.966} & \multirow[t]{2}{*}{2} & \multirow{2}{*}{$\begin{array}{c}5.99 \\
\text { S* }\end{array}$} \\
\hline & & No & 30 & 38 & 1 & & & \\
\hline \multirow[t]{4}{*}{5} & \multirow{4}{*}{$\begin{array}{l}\text { Working Hrs. } \\
\text { per week }\end{array}$} & $<20$ & 2 & 1 & 1 & \multirow[t]{4}{*}{8.496} & \multirow[t]{4}{*}{6} & \multirow{4}{*}{$\begin{array}{l}12.6 \\
\mathrm{NS}\end{array}$} \\
\hline & & $20-30$ & 4 & 20 & 5 & & & \\
\hline & & $30-40$ & 23 & 35 & 5 & & & \\
\hline & & $>40$ & 2 & 2 & 0 & & & \\
\hline \multirow[t]{4}{*}{6} & \multirow[t]{4}{*}{ Area of service } & Orthopedic & 5 & 11 & 3 & \multirow[t]{4}{*}{1.648} & 6 & 12.6 \\
\hline & & Neurological & 8 & 17 & 2 & & & NS \\
\hline & & Cardiovascular & 9 & 16 & 4 & & & \\
\hline & & Others & 9 & 14 & 2 & & & \\
\hline 7 & Patient care & Pediatric & 9 & 14 & 1 & 10.191 & 6 & 12.6 \\
\hline & age group & Adult & 15 & 30 & 5 & & & NS \\
\hline & & Geriatric & 7 & 14 & 4 & & & \\
\hline & & Others & 0 & 0 & 1 & & & \\
\hline
\end{tabular}

Among the background variables of study participants, professional education and participation in continuing education were significantly associated with attitude towards innovative approaches in staff nurses.

\section{Discussion}

Although several studies has been conducted about innovation and EBP in nursing profession, but attitude of nurses working in ICUs towards innovation \& EBP have not been investigated. Thus the major emphasis in this study was on the attitude of staff nurses working in ICUs towards innovation and EBP in nursing care. This 


\section{Original Research Article}

study was designed specifically to describe ICU nurse's attitude towards innovative approaches in nursing care. The results of study indicated that majority of staff nurses have positive attitude towards innovation and EBP followed by neutral and strong positive attitude towards innovation. These results were supported by previous studies describing attitude of nurses towards EBP [4].

Findings of study showed positive attitude among nurses towards self efficacy in use of innovative approaches among nurses. The result of current study in contrary with previous study is opposite as it showed unfavorable attitude with weak self efficacy in EBP. More studies are needed to explore the attitude [5].

Nurses showed neutral attitude in relation to barriers to adopting innovation in practice. The factors are lack of time, understanding of research, resources and judgment of quality research.

Similar factors identified by study conducted in Maldives which reported the non availability of relevant literature, insufficient time to implement innovation and permission from administration as barriers to adopting innovation $[6,7]$.

This study finds a positive attitude towards personal use and understanding of clinical practice guideline, these results are supported by cross sectional survey conducted by Davis Quiros et al [8]. The present study revealed the limited availability to access innovative and EBP among nurses and the attitude is neutral, similar results reported by previous studies where researcher find inadequate utilization of research, and lack of resources as barrier in innovation [7,12].

Attitude towards new practices in nursing care is positive as majority of nurses believe in use of new communicative devices, use of electronic health record and practice of high fidelity simulator in nursing care. The results are supportedby similar studies $[9,10,11]$.

Result of the study showed, that majority of staff nurses of age group 30-49 years having positive attitude towards innovation. Fenzhou et al finds longer work experience and lighter work load facilitate professional attitude towards EBP [13].

Male nurses working in ICUs have more positive attitude compared to female nurses, similar results reported by $\mathrm{Abu}$ Ruz ME et al [4]. Considering professional education of nurses, baccalaureate education showed strong positive attitude towards innovation, the similar results found in study conducted by Mathew K Kipturgo [9]. Continuing education has a main role in developing attitude of nurses as those participated in these programme showed strong positive attitude towards innovation and EBP.

Masoumehshohani founds the similar results and significant relationship between attitude and participation in training courses [14].

Providing research training opportunities and educational programme to nurses for health care organization seeking to promote EBP is a promising strategy reported by Agnes $\mathrm{T}$ Black et al [15]. Development of positive attitude towards innovationin nursing practice isimportant for professional growth as well as quality care. The key facilitating factors for EBP include support, encouragement and recognition by authorities.

\section{Conclusion}

This study revealed a positive attitude among staff nurses towardsinnovation is nursing care, professionally higher educated and participation in continuing education of staff nurses have positive attitude towards innovation in nursing care. There are barriers also hindering nurses from adopting EBPie. availability to access innovative and evidence based practice. Gap between research and nursing practice need be minimized by continuing education; seminar and training on use of innovative approaches in nursing practice.

Coauthor's contribution: Yadav A helped in theoretical formalism, verified the analytical methods and supervised the findings of this work and contributed to discussion and final manuscript.

What does this study add to existing knowledge: This study conducted with aim to find nurses attitude towards innovation in nursing practice. Though many other studies has been conducted in nursing profession on perception and attitude, ICUs are special areas of care to patients with critical conditions and the practice in these settings are constantly changing with technical advancement. To adopt a change in practice need a positive attitude towards the change. This study has contributed in finding the attitude of ICU nurses towards innovation and EBP.

Funding: Nil, Conflict of interest: None

Permission of IRB: Yes 


\section{References}

1. Nurses leading care innovation. Geneva: International council of nurses. 2009

2. Sanders $C^{1}$, Rogers A, Bowen R, et al. Exploring barriers to participation and adoption of telehealth and telecare within the Whole System Demonstrator trial: a qualitative study. BMC Health Serv Res. 2012 Jul 26; 12: 220. doi: 10.1186/1472-6963-12-220.

3. Taylor J, Coates E, Brewster L, et al. Examining the use of telehealth in community nursing: identifying the factors affecting frontline staff acceptance and telehealth adoption. J Adv Nurs. 2015 Feb;71(2):32637. doi: 10.1111/jan.12480. Epub 2014 Jul 29.

4. AbuRuz ME, Hayeah HA, Al-Dweik G, et al. Knowledge, Attitudes, and Practice about EvidenceBased Practice: A Jordanian Study.HealthSci J. 2017, 11: 2. DOI: $10.21767 / 1791-809 X .1000489$

5. Farokhzadian J, Nayeri ND, Borhani F, et al. Nurse leaders' Attitudes, Self-Efficacy and training Needs for Implementing Evidence-Based Practice: Is It Time for a Change toward Safe Care? Br J Med Med Res. 2015; 7(8): 662-671. Epub 2015 Mar 17.

6. FathimathShifaza, David Evans, and Helen Bradley. Nurses' Perceptions of Barriers and Facilitators to Implement EBP in the Maldives. Hindawi Publishing Corporation Advances in Nursing Volume 2014, http://dx.doi.org/10.1155/2014/698604

7. Magda M. Mohsen1, NahlaAshour Safaan1, Omayma M. Okby. Nurses' Perceptions and Barriers for Adoption of Evidence Based Practice in Primary Care: Bridging the Gap American Journal of Nursing Research, 2016, Vol. 4, No. 2, 25-33 http://pubs. sciepub. com/ajnr/4/2/1DOI:10.12691/ajnr-4-2-1

8. Quiros D, Lin S, Larson EL. Attitudes toward practice guidelines among intensive care unit personnel: a cross-sectional anonymous survey. Heart Lung. 2007 Jul-Aug; 36 (4):287-97. DOI:10.1016/j. hrtlng. 2006.08.005
9. Kipturgo MK, Kivuti-Bitok LW, Karani AK, et al. Attitudes of nursing staff towards computerisation: a case of two hospitals in Nairobi, Kenya. BMC Med Inform DecisMak. 2014 Apr 29;14:35. doi: 10.1186/ 1472-6947-14-35.

10. Tubaishat A. An investigation into the attitudes of nursing students toward technology. J Nurs Res. 2014 Jun; 22 (2):119-25. doi: 10. 1097/jnr.000000000000 0029 .

11. Chang-Chiao Hung et al., Effects of simulationbased learning on nursing student competences. J Nurs Care 2016, 5:4(Suppl) http://dx.doi.org/10.4172/21671168.C1.020

12. Ofi B, Sowunmi L, Edet D, et al. Professional nurses' opinion on research and research utilization for promoting quality nursing care in selected teaching hospitals in Nigeria. Int J Nurs Pract. 2008 Jun; 14(3):243-55. doi: 10. 1111/j. 1440-172X. 2008. 00 684.x.

13. Fen Zhou, YufangHao, Hong Guo, Hongxia Liu. Attitude, Knowledge, and Practice on Evidence-Based Nursing among Registered Nurses in Traditional Chinese Medicine Hospitals: A Multiple Center CrossSectional Survey in China. Evidence-Based Complementary and Alternative Medicine. Volume 2016, Article ID 5478086, http://dx.doi.org/10. 1155 /2016/5478086

14. Masoumeh Shohani1, Vahid Zamanzadeh. Nurses' Attitude towards Professionalization and Factors Influencing It. Journal of Caring Sciences, 2017, 6(4), 345-357 doi:10.15171/jcs.2017.033

15. Black AT, Balneaves LG, Garossino C, et al. Promoting evidence-based practice through a research training program for point-of-care clinicians. J Nurs Adm. 2015 Jan;45(1):14-20. doi: 10.1097/NNA.000000 0000000151 .

\section{How to cite this article?}

Jangir G, Yadav A. Assessment of attitude towards innovative approaches related to nursing care in intensive care units among staff nurses of P.B.M. Hospital, Bikaner. Int J Med Res Rev 2018;6(08):458-463. doi:10.17511/ijmrr.2018.i08.10. 